\title{
Stroke Prevention with Non-Vitamin K Oral Anticoagulants: For Most, but Not for All!
}

\author{
Jan Steffel \\ Division of Electrophysiology and Cardiac Devices, Department of Cardiology, University Heart Center Zurich, \\ Zurich, Switzerland
}

Based on their at least similar efficacy and better safety profiles, non-vitamin $\mathrm{K}$ oral anticoagulants (NOACs) have become the standard of care for stroke prevention in patients with non-valvular atrial fibrillation (AF) [1-5]. In the current issue of Cardiology, Carvalho Silva et al. [6] report on the outcome of a patient with a mechanical mitral valve, who was changed from warfarin to rivaroxaban and half a year later presented with the typical symptoms of valve thrombosis. He was treated by re-do mitral valve replacement, and fortunately the operation as well as the postoperative course were uneventful.

The case is important and illustrates very well some of the important challenges we face in the current era of NOACs. The almost unanimously positive results from the above-mentioned landmark randomized clinical trials as well as subsequent registry data led to a paradigm shift in stroke prevention in "non-valvular" AF. Indeed, the 2016 European Guidelines [7] as well as the 2019 AHA/ACC/HRS guidelines [8] now recommend NOACs as the standard of care for most patients with AF requiring anticoagulation.

The situation is less clear, however, for patients with "valvular" AF. Part of the problem is the lack of homogeneity regarding its definition, which is why current ESC guidelines have more or less abandoned its use [7], and the European Heart Rhythm Association (EHRA) has introduced a new concept consisting of "EHRA 1" and

\section{KARGER}

๑) 2019 S. Karger AG, Basel

E-Mail karger@karger.com

www.karger.com/crd
"EHRA 2" [9]. In addition, the inclusion criteria for the trials were not the same throughout; for example, bioprosthetic valves were allowed in ARISTOTLE and ENGAGE AF-TIMI 48, but not in ROCKET-AF [2-4]. Importantly, however, mechanical heart valves and rheumatic mitral stenosis were excluded in all four of the phase III NOAC trials.

Moreover, the Re-ALIGN trial investigating dabigatran as anticoagulation after mechanical heart valve implantation had to be prematurely due to an excess in thromboembolic as well as bleeding complications in the NOAC arm $[10,11]$. There are several potential pathophysiological differences in stroke prevention in AF versus prevention of thrombus formation after mechanical valve implantation, including thrombus formation as a result of exposure of foreign material in the latter, which may require a more continuous and more "upstream" (i.e., factor VIIa/TF-targeted) anticoagulation. However, also the design of Re-ALIGN including the selection of the dose of dabigatran as well as the time window for inclusion may have contributed to its outcomes [11]. Indeed, the amount of dabigatran used in Re-ALIGN was not specifically tested in a dedicated phase II study but rather extrapolated from the Re-LY trial and preclinical animal data, resulting in doses equal to or substantially higher than those given in Re-LY (150-300 mg b.i.d. in Re-ALIGN). In addition, most patients $(80 \%)$ were re- 
cruited into the trial in the immediate postoperative period (3-7 days after surgery), hence in a phase where the risk of bleeding as well as that of thromboembolism is increased. It therefore comes with no surprise that the majority of complications occurred in exactly these patients. Inclusion of patients in a more stable phase; e.g., 6-12 months after the operation, may have led to much less perioperative "noise" and may have possibly been able to determine the true efficacy and safety of dabigatran in this patient population [11].

Be it as it is, the results of Re-ALIGN have contributed to the clear contraindication of the use of NOACs in patients with mechanical heart valves. The situation is less clear in patients after biological valve implantation. Usually, outside the postoperative period where vitamin-K antagonists (VKA) are mandatory in these individuals, they are switched to aspirin after postoperative months 3-6 (until 12 months) when reendothelialization is presumed to be complete, especially after biological aortic valve implantation. In a patient with $\mathrm{AF}$ after biological aortic valve implantation, substituting a NOAC for VKA when they would usually be switched to aspirin may hence be feasible [12].

For biological mitral valve replacement, the situation is less clear, since thrombogenicity is higher; this of course is particularly true for mechanical valves in the mitral position, as it was the case for the presented patient [6]. We usually do not even recommend NOACs in patients who receive a biological mitral valve replacement after rheumatic mitral stenosis [12]. Although the rheology of the mitral valve has been restored in these patients, their atria are usually greatly enlarged, and the substrate of their atrial myopathy frequently remains unchanged. As such, these patients should be treated with VKA until further data are available. In contrast, patients with AF after biological aortic valve implantations (or, possibly, after biological mitral valve replacement for degenerative mitral regurgitation) may be given a NOAC outside the initial "mandatory" postoperative period with VKA.
In the unfortunate situation of the presented case, warfarin was changed to the NOAC likely with good intentions but in the lack of knowledge that in patients with mechanical prosthetic valve - even more so in the mitral position - this is contraindicated. The case therefore once more underlines the importance of continuing our intense educational efforts on stroke prevention in $\mathrm{AF}$ and the proper use of NOACs [12]. With four drugs available in different indications (including stroke prevention, treatment of deep vein thrombosis/pulmonary embolism, prevention of deep vein thrombosis, etc.) with varying dosages and different patient populations, the potential for confusion is enormous. A good example is the recently published COMPASS trial, where addition of a very low dose of rivaroxaban $(2 \times 2.5 \mathrm{mg}$ - numerically identical to the reduced dose of apixaban for stroke prevention in $\mathrm{AF}$ ) was shown to be beneficial in patients with chronic coronary artery disease - but without AF! [13]

Things have become more complicated over the last 10 years; there does not seem to be a "one-size-fits-all solution," and a balanced, patient-tailored use of NOACs seems to be the way to go. And indeed, recent data indicate that the proper usage of these novel agents may pay out: registries from both the UK and Sweden observed for the first time a reduced incidence in ischemic stroke in $\mathrm{AF}$ patients $[14,15]$. Hence, NOACs, if correctly used for the right patients, carries a great potential in stroke prevention in $\mathrm{AF}$ - for most, but not for all patients, as the current case nicely illustrates.

\section{Disclosure Statement}

Dr. Steffel has received consultant and/or speaker fees from Abbott, Amgen, Astra-Zeneca, Atricure, Bayer, Biosense Webster, Biotronik, Boehringer-Ingelheim, Boston Scientific, Bristol-Myers Squibb, Daiichi Sankyo, Medscape, Medtronic, Merck/MSD, Novartis, Pfizer, Sanofi-Aventis, WebMD, and Zoll. He reports ownership of CorXL. Dr. Steffel has received grant support through his institution from Abbott, Bayer Healthcare, Biosense Webster, Biotronik, Boston Scientific, Daiichi Sankyo, and Medtronic.

\section{References}

1 Connolly SJ, Ezekowitz MD, Yusuf S, Eikelboom J, Oldgren J, Parekh A, et al.; RE-LY Steering Committee and Investigators. Dabigatran versus warfarin in patients with atrial fibrillation. N Engl J Med. 2009 Sep;361(12): 1139-51.

2 Patel MR, Mahaffey KW, Garg J, Pan G, Singer DE, Hacke W, et al.; ROCKET AF Investi- gators. Rivaroxaban versus warfarin in nonvalvular atrial fibrillation. $\mathrm{N}$ Engl J Med. 2011 Sep;365(10):883-91.

3 Granger $\mathrm{CB}$, Alexander $\mathrm{JH}$, McMurray JJ, Lopes RD, Hylek EM, Hanna M, et al.; ARISTOTLE Committees and Investigators. Apixaban versus warfarin in patients with atrial fibrillation. N Engl J Med. 2011 Sep;365(11):981-92.
4 Giugliano RP, RuffCT, Braunwald E, Murphy SA, Wiviott SD, Halperin JL, et al.; ENGAGE AF-TIMI 48 Investigators. Edoxaban versus warfarin in patients with atrial fibrillation. $\mathrm{N}$ Engl J Med. 2013 Nov;369(22):2093-104.

5 Steffel J, Ruff CT, Goldhaber S, Brunckhorst C. Stroke prevention in atrial fibrillation. Bremen: UniMed; 2014. 
6 Carvalho Silva DM, Braga A, de Jesus I, Neves J. Mechanical prosthetic heart valve thrombosis in a patient receiving rivaroxaban. Cardiology. DOI: 10.1159/000501361.

7 Kirchhof P, Benussi S, Kotecha D, Ahlsson A, Atar D, Casadei B, et al.; ESC Scientific Document Group. 2016 ESC Guidelines for the management of atrial fibrillation developed in collaboration with EACTS. Eur Heart J. 2016 Oct;37(38):2893-962.

8 January CT, Wann LS, Calkins H, Field ME, Chen LY, Furie KL, et al. 2019 AHA/ACC/ HRS Focused Update of the 2014 AHA/ACC/ HRS Guideline for the Management of Patients With Atrial Fibrillation: A Report of the American College of Cardiology/American Heart Association Task Force on Clinical Practice Guidelines and the Heart Rhythm Society. Heart Rhythm. 2019 Jan;S15475271(19)30037-2.

9 Lip GY, Collet JP, Caterina R, Fauchier L, Lane DA, Larsen TB, et al.; ESC Scientific Document Group. Antithrombotic therapy in atrial fibrillation associated with valvular heart disease: a joint consensus document from the European Heart Rhythm Association (EHRA) and European Society of Cardiology Working Group on Thrombosis, endorsed by the ESC Working Group on Valvular Heart Disease, Cardiac Arrhythmia Society of Southern Africa (CASSA), Heart Rhythm Society (HRS), Asia Pacific Heart Rhythm Society (APHRS), South African Heart (SA Heart) Association and Sociedad Latinoamericana de Estimulación Cardíaca y Electrofisiología (SOLEACE). Europace. 2017 Nov;19(11):1757-8.

10 Eikelboom JW, Connolly SJ, Brueckmann M, Granger CB, Kappetein AP, Mack MJ, et al.; RE-ALIGN Investigators. Dabigatran versus warfarin in patients with mechanical heart valves. N Engl J Med. 2013 Sep;369(13): 1206-14.

11 Steffel J, Atar D. Non-vitamin K oral anticoagulants in 'valvular' atrial fibrillation: a call for action. Europace. $2016 \mathrm{Jan} ; 18(1): 1-3$.

12 Steffel J, Verhamme P, Potpara TS, Albaladejo P, Antz M, Desteghe L, et al.; ESC
Scientific Document Group. The 2018 European Heart Rhythm Association Practical Guide on the use of non-vitamin K antagonist oral anticoagulants in patients with atrial fibrillation. Eur Heart J. 2018 Apr;39(16): 1330-93.

13 Eikelboom JW, Connolly SJ, Bosch J, Dagenais GR, Hart RG, Shestakovska O, et al.; COMPASS Investigators. Rivaroxaban with or without Aspirin in Stable Cardiovascular Disease. N Engl J Med. 2017 Oct;377(14): 1319-30.

14 Cowan JC, Wu J, Hall M, Orlowski A, West RM, Gale CP. A 10 year study of hospitalized atrial fibrillation-related stroke in England and its association with uptake of oral anticoagulation. Eur Heart J. 2018 Aug;39(32): 2975-83.

15 Forslund T, Komen JJ, Andersen M, Wettermark B, von Euler M, Mantel-Teeuwisse AK, et al. Improved Stroke Prevention in Atrial Fibrillation After the Introduction of Non-Vitamin K Antagonist Oral Anticoagulants. Stroke. 2018 Sep;49(9):2122-8. 